\title{
What Makes British Musicals Uniquely British?
}

\author{
Tereza Zálešáková
}

Robert Gordon, Olaf Jubin and Millie Taylor. British Musical Theatre since 1950. London: Bloomsbury Methuen Drama, 2016. 288 pp.

'British musical theatre has made an international impact in four distinct historical epochs: (a) Eighteenth-century ballad opera; (b) Gilbert and Sullivan's comic opera between 1871 and 1896; (c) English musical comedy between 1892 and 1918; and (d) the explosion of British musicals globally since Jesus Christ Superstar.' (1)

British Musical Theatre since 1950 (first published 2016) is one of the first book results of musical theatre study initiatives in Britain (2006 - an international conference named Song, Stage and Screen; 2007 - the first academic journal Studies in $M u$ sical Theatre; 2012 - the inauguration of British Musical Theatre Research Institute).

Robert Gordon, Olaf Jubin and Millie Taylor participated on the content of British Musical Theatre since 1950. They view musical theatre differently; therefore, the book is divided into three separate parts. As the introduction states: '[t]he authors have made no attempt to 'harmonize' their views or integrate their perspectives to produce a single approach to a multidisciplinary field of study.' (5) As questionable as this decision may seem, it enables a more extensive and thorough research. Thus, their anthology does not offer only one compact and fluent view of the British musical, but rather three different, specific parts (differing both in focus and style), each using an individual approach. Every part consists of essays/overview chapters and four case studies.

\section{Staging Political Protest - 'Merry Christmas, Maggie Thatcher'}

The musical (as well as other theatre genres) is perfectly capable of reflecting both directly or indirectly on conditions and circumstances of the era in which it was created. Yet, Gordon admits this level can be more difficult to observe regarding musicals due to their commercial purposes. Nevertheless, Gordon aims to elucidate the link between British musical theatre and several socio-political events in Great Britain after the Second World War. His four case studies are thus based on various eras from performances of the 1950s to current productions in the London West End.

His case studies focus on the following musicals: Salad Days, ${ }^{1}$ Blood Brothers, Billy Elliot and Matilda: The Musical. Gordon very carefully outlines how socio-political circumstances are reflected both in the contents and the form of particular musicals. Post-war deprivation, nostalgia, homosexuality, social inequality, the impact of left-oriented politics, the postmodern family, upbringing and the education system - those are just examples of topics this part of the book deals with.

A reflection of Margaret Thatcher's government and its reflection in musical

\footnotetext{
1 'One of the biggest smashes in London before Lloyd Webber came along' (GORDON, JUBIN and TAYLOR 2016: 158).
} 
theatre becomes a significant topic. This particular issue is discussed in Case Study 2 (Blood Brothers) and especially in Case Study 3 (Billy Elliot). These examples consider the era (Thatcherism) in question as both a synchronically 'live' experience during the 1980s (Blood Brothers), and also as a subject viewed with historical distance from the new-millennium (Billy Elliot). Billy Elliot brings Margaret Thatcher on stage in form of a traditional British Christmas entertainment, a pantomime-style intermezzo show-within-a-show that takes place immediately after the interval. Case Study 3 is the most extensive and complex analysis in the book. Gordon proves that British musical theatre is not only about celebration of individual triumph, but rather of community spirit and social rapprochement.

\section{Who's Speaking, and to Whom?}

Millie Taylor deals with British musical theatre from a different perspective. Part II called British Popular Culture and Musical Theatre, is devoted primarily to the diversity of both British musicals and their audience.

A concept of gradually revealed nostalgia becomes one of the distinctive features of British musicals, much like the impact of multiculturalism on both local and mainstream British popular culture and the impact of changing popular music on musicals. According to Taylor, contemporary British musical theatre is primarily affected and influenced by multiculturalism.

Taylor connects the British musical theatre tradition to Brechtian aesthetics and Joan Littlewood's creative techniques (es- pecially in Case Study 5: Oh What a Lovely War!) and her impact on subsequent creators. Taylor discusses the influence of popular culture and the traditions of former British colonies in Case Study 6: Bombay Dreams. Indeed, the highlight of this part is Case Study 8: The Rocky Horror Show, which focuses on the gradual growth of an audience's interaction during an entirety of productions (thus, within all performances of a given show).

Taylor's case studies are not as extensive as those provided by Gordon and Jubin. However, a crucial part of Taylor's case studies lies in her analysis of musical dramaturgy. In this regard, Taylor focuses on particular musicals and exemplifies how the use of different styles and genres helps to create characters and meaning (Case Study 7: Oliver!, Case Study 8: The Rocky Horror Show).

This section deals with large quantities of information devoted to local and minority (non-mainstream) British theatre projects; therefore, it could have been divided into smaller sequences or subchapters. However, all Taylor's texts provide their reader with a significant number of useful and valuable facts.

\section{Ingredients for a Worldwide Smash}

Olaf Jubin's Part III entitled Narrative and Story-Telling in the British Musical since 1970 deals with the close reading of librettos and lyrics. Jubin focuses on the genesis of a libretto through several stages (mirrored in the essays). These include: concept recordings, sung-through shows, stage adaptations of novels and other literary works, original stories, 'jukebox' musicals, and film adaptations. 
Jubin considers not only the West End's musical highlights; he also accounts for some less successful productions or utter flops, while trying to find out the cause of their failure. Besides, it is remarkable to observe the transformation of what 'failure' means - which mainly now rests on recouping current major financial demands.

Jubin rigorously collects all the materials written (or heard) on the subject. Quotations are not based solely on scholarly publications. Jubin exploits both reviews and audience comments in order to depict a diversity of approaches and perspectives of reviewers and scholars worldwide.

His case studies focus on the greatest hits of British musical theatre since 1970: Jesus Christ Superstar, Les Misérables, The Phantom of the Opera and Mamma Mia!. Yet, he includes a large number of other British or foreign musicals. Through this wideranging survey, Jubin unravels the web of carefully constructed inherent libretto coherence; he explains the importance of song placement in a narrative structure and interprets some details that co-create the meaning and characters; those that can be ignored or misunderstood during the staging (such as the matter of Judas' and Jesus' free will in Jesus Christ Superstar, or various ways of depicting faith in Les Misérables). The final case study looks into the success of Mamma Mia! as a humorous smash culmination of perfectly compact parts. In fact, as Millie Taylor also reveals in Part II, the roots of aesthetics in this 'new' sub-genre, the so-called 'jukebox' musical, go deeper into the British musical theatre tradition than expected.

Besides the essays and case studies, the volume also contains a timeline of musicals and political events (bizarrely, Blood Brothers fell off the list, probably by accident).
This useful temporal map is followed by an appendix, a selective bibliography, a discography and a filmography. As there is a large number of notes and quotations, it might make the reading more fluent if these were placed in the text.

Even considering the number of books that have been published on musical theatre so far, this one is still a rarity. The authors of British Musical Theatre since 1950 try to free British musical theatre from the perspectives of Broadway custom, from which they are usually perceived and judged. In many cases, such an approach leads to a misunderstanding and a misclassification of the category of 'British musical theatre'. In approaching British theatre from the perspective of Broadway custom, such publications too often disregard many of the historical developments and traditional sources of musical entertainment genres in British theatre.

In British Musical Theatre since 1950, the authors focus quite simply on British musical theatre history, related genres, and the impact on more up-to-date pieces of work. All three authors reveal traces of traditional British theatre genres like camp, British pantomime, Christmas pantomime, or the 'jukebox' musical, among others.

In conclusion, British Musical Theatre since 1950 is a noteworthy publication on the capacious British musical theatre tradition; moreover, it validates the position of the artform in British popular and artistic culture. The volume deals with many world famous shows (especially in the case studies) and it is this very showcase of the British musical theatre, that shows many of the concrete and individual aspects that make British musicals truly and entirely 'British'. 